$\Phi=$ 原

\title{
Geoelectrical and geotechnical investigation of foundation failure in and around Oroke high school, Akungba- Akoko, southwestern Nigeria
}

\author{
Odundun, O. A. ${ }^{1}$, Fagorite, V. I. ${ }^{2}$, Rogbitan, E. O. ${ }^{1}$ \\ ${ }^{1}$ Department of Earth Sciences, Adekunle Ajasin University, Akungba Akoko, Nigeria \\ ${ }^{2}$ Department of Geology, Federal University of Technology, Owerri, Nigeria \\ *Corresponding author E-mail: smeks@yahoo.fr
}

\begin{abstract}
Engineering structures are designed and constructed with an air of lifelong expectancy. Moreover, building foundation may experience failure due to presence of concealed geologic features such as cavity and shear zones which can lead to subsurface subsidence. Hence, it is imperative, prior to building construction, to investigate the physical properties of foundation soils and determine its suitability for design and construction of building structures. In the light of this, a geoelectric survey, involving three (3) electrical dipole - dipole array and geotechnical analysis methods were carried out around a distressed building at Oroke High School, opposite Adekunle Ajasin University, Akungba Akoko to establish the cause of failure for the structures foundation via delineating the subsurface structural features. The field electrical data were plotted on $\log$ - $\log$ graph sheets and the resulting curves were interpreted qualitatively by visual inspection, and quantitatively via partial curve matching and computer iteration techniques. For the geotechnical analysis, a total of twelve (12) soil samples were taken from different locations of about 30 meters intervals, at the depth of 1.5 meters. The pseudo - section and electrical sections indicate that the subsurface is heterogeneous in geological composition. The $2 \mathrm{D}$ dipole- dipole resistivity and pseudo - section delineated zones having resistivity values ranging from 200 to $700 \mathrm{ohm}$ meter, and those approaching infinity all within a depth of 0-5 m, the resistivity values of 27 to $139 \mathrm{ohm}$ meter suggest the presence of clay. The geoelectric section identified three subsurface geologic layers comprising clay /sandy, clay top soil / sub grade soil, clay / sandy clay and sand weathered layer and the basement (fresh) beneath the failed segment. Additionally, prominent fractures were discovered within some areas on the pseudo-sections. The results of the laboratory tests also included those of natural moisture content, specific gravity, grain size distribution curves, Atterberg limit, compaction test and California Bearing Ratio (CBR). In conclusion, electrical resistivity method was found to be an effective measure or tool in the site characterization. The soil/rock in these zones may require reinforcement in order to enhance its bearing capacity and increase the life span of the engineering foundation.
\end{abstract}

Keywords: Geoelectrical; Geotechnical; Dipole-Dipole and Foundation.

\section{Introduction}

Building failure(s) could be defined as a discontinuity in structure, resulting in cracks, bulges and depressions (Aigbedion, 2007). However, waviness was adjudged the most common form of building failure (Gidigasu, 1972). Buildings of various categories in Nigeria have shown signs of failure in the form of cracking, rutting, deformation and peeling. In some cases, these signs of distress are visible within a short period of commissioning, yet the causes have not been fully established.

Engineering structures are designed and constructed with an air of lifelong expectancy. Moreover, building foundation may experience failure due to presence of concealed geologic features such as cavity and shear zones which can lead to subsurface subsidence (Fajana et al., 2016).Therefore, there is a need to investigate the geo-properties of foundation soils and determine how suitable they are for use as engineering materials. The geotechnical and geophysical methods are most suitable for this purpose of investigation as they provide information about the engineering properties of the foundation soils in relatively cost-effective and rapid manner (Oyedele and Bankole, 2009). Majority of building failures in the tropics can be attributed to geotechnical and geophysical factors as reported by workers such as Gidigasu (1972), Meshida (1985) and Adeyemi (1990) while other workers (Momoh et al., 2008) considered poor construction materials, bad design as some of the factors responsible for the failures. The aim of this research is to establish the cause of the failure for the structures foundation via delineating the subsurface structural features.

\section{Description of the study area}

The study area is located within Oroke High School, opposite Adekunle Ajasin University Campus, Akungba-Akoko, Ondo State, Nigeria. It falls within latitudes N $070^{\circ} 28^{\prime} 45.41^{\prime \prime}$ and N070 $28^{\prime} 54.62^{\prime \prime}$ and Longitudes E005 $44^{\prime} 8.617^{\prime \prime}$ and E005 $44^{\prime} 18.064^{\prime \prime}$. The study area covers 
an estimated area of about 1.4 square kilometers. It has an approximated elevation of about $340 \mathrm{~m}$ and enclosed within the Nigeria topographic sheet 255 (Owo Sheet belt).

The topography of the area is characterized by highlands and low lands with the Northern part having topographically higher elevations than the Southern parts. The highlands are made up migmatite gneiss rocks which form inselbergs while the lowlands are valleys and plains covered by laterite (Ademeso and Adeyeye, 2011). The highest elevation in the region is slightly over 1820ft above the sea level (Figure $1)$.

The study area lies within the crystalline Basement Complex rocks of the Southwestern Nigeria. The main rocks recognised in the study area are Grey gneiss, Granite gneiss and Migmatite (Figure 3).

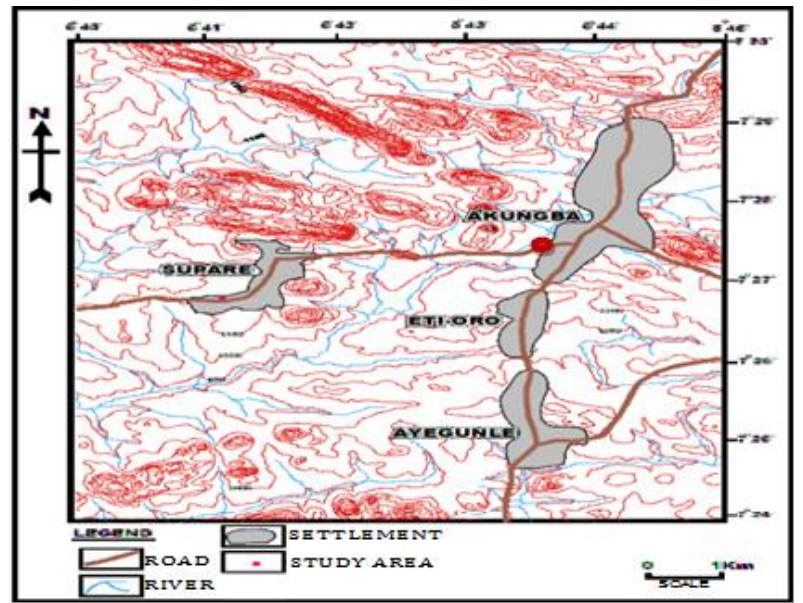

Fig. 1: Topographic Maps of Akungba and Its Environs (Source: Department of Geology, Aaua).
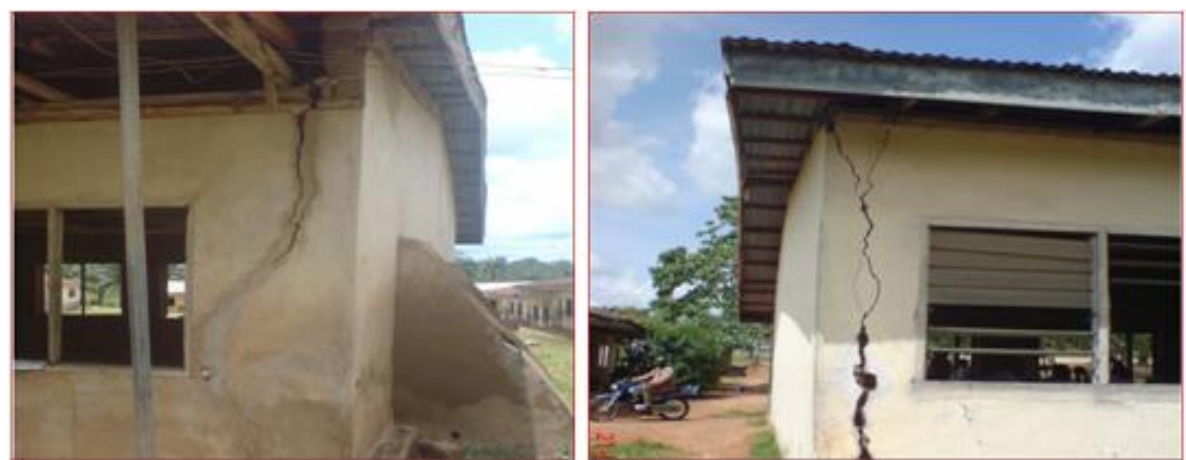

Fig. 2: Typical Cracks Along Building Walls in the Study Area.

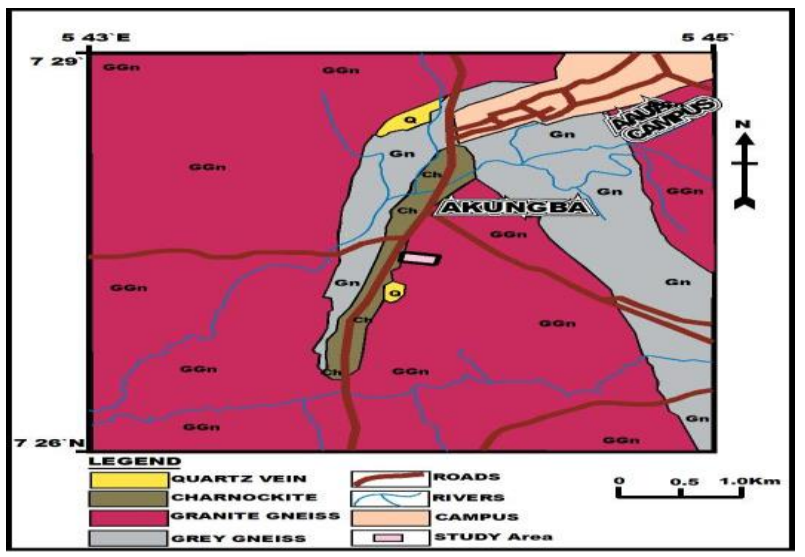

Fig. 3: Geological Map of the Study Area. Source: (After Geological Survey of Nigeria, 2015).

\section{Methodology}

Electrical and geoelectric survey, involving three dipole - dipole array and geotechnical analysis methods, were carried out around a distressed building at Oroke High School, opposite Adekunle Ajasin University, Akungba Akoko. The field electrical data were plotted on $\log -\log$ graph sheets and the resulting curves were interpreted qualitatively by visual inspection, and quantitatively via partial curve matching and computer iteration techniques. For the geotechnical analysis, a total of twelve (12) soil samples were taken from different locations of about 30 meters intervals, at the depth of 1.5 meters. The collected soil samples from each horizon of the profiles were analyzed at the soil mechanical laboratory of Department of Earth Sciences, Adekunle Ajasin University, Akungba-Akoko. The soil samples were geotechnically tested according to the BS 1377 (1990) procedures.

The geophysical and geotechnical instruments used in this study include the following:

i) ABEM SAS 1000 Terrameter Equipment. 
ii) Resistivity Meter.

iii) Electrodes (Metallic).

iv) Reels of Connecting Cables.

v) Tapes, thread, pegs, hammers, digger, chisel and cutlasses.

vi) Compass Clinometer and Global Positioning System (GPS)

vii) Sample bags

\subsection{Dipole - dipole array}

The dipole -dipole array has been, and is still, widely used in resistivity/I.P. surveys because of the low E.M. coupling between the current and potential circuits. The dipole-dipole electrode array consists of two sets of electrodes, the current (source) and potential (receiver) electrodes. The convention for a dipole-dipole electrode array is to maintain an equal distance for both the current and the potential electrodes ( spacing $=\mathrm{a}$ ), with the distance between the current and potential electrodes as an integer multiple of a. The electrodes do not need to be located along a common survey line (Aminu et al., 2014).

Additionally, the dipole - dipole data was interpreted via inverse modelling (automatic interpretation) using Dippro ${ }^{\mathrm{TM}}$ SOFTWARE which is followed by qualitative interpretation of the generated pseudo-sections.

\subsection{Laboratory ananlysis}

Laboratory testing of the undisturbed soil samples collected at the established locations proceeded. The following analyses were conducted on the samples collected.

i) Natural moisture content (NMC)

ii) Atterberg or consistency limit test (Liquid Limit, Plastic Limit, Plasticity index, Linear Shrinkage)

iii) Specific gravity

iv) Grain size analysis

v) Compaction test

vi) California bearing ratio $(\mathrm{CBR})$

\section{Dipole - Dipole Array}

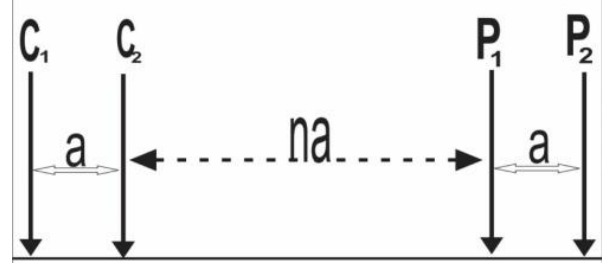

Fig. 4: Diagram Showing Dipole - Dipole Array Configuration.

Table 1: Longitude, Latitude and Elevation of the Sample Points

\begin{tabular}{|c|c|c|c|}
\hline Samples & Latitude & Longitude & Elevation $(\mathrm{m})$ \\
\hline L1 & $7^{0} 28^{\prime} 54.63^{\prime \prime} \mathrm{N}$ & $5^{0} 44^{\prime} 18.06 " \mathrm{E}$ & 361 \\
\hline L2 & $7^{0} 28^{\prime} 53.30^{\prime \prime} \mathrm{N}$ & $5^{0} 44^{\prime} 15.98 " \mathrm{E}$ & 350 \\
\hline L3 & $7^{0} 28^{\prime} 54.35^{\prime \prime} \mathrm{N}$ & $5^{0} 44^{\prime} 15.00^{\prime \prime} \mathrm{E}$ & 360 \\
\hline L4 & $7^{0} 28^{\prime} 53.50^{\prime \prime} \mathrm{N}$ & $5^{0} 44^{\prime} 10.5^{\prime \prime} \mathrm{E}$ & 346 \\
\hline L5 & $7^{0} 28^{\prime} 53.38^{\prime \prime} \mathrm{N}$ & $5^{0} 44^{\prime} 13.33^{\prime \prime} \mathrm{E}$ & 346 \\
\hline L6 & $7^{0} 28^{\prime} 48.82^{\prime \prime} \mathrm{N}$ & $5^{0} 44^{\prime} 12.30^{\prime \prime} \mathrm{E}$ & 345 \\
\hline L7 & $7^{0} 28^{\prime} 49.89^{\prime \prime} \mathrm{N}$ & $5^{0} 44^{\prime} 19.95 " \mathrm{E}$ & 340 \\
\hline L8 & $7^{0} 28^{\prime} 48.09^{\prime \prime} \mathrm{N}$ & $5^{0} 44^{\prime} 19.67 " \mathrm{E}$ & 335 \\
\hline L9 & $7^{0} 28^{\prime} 45.42^{\prime \prime} \mathrm{N}$ & $5^{0} 44^{\prime} 13.10^{\prime \prime} \mathrm{E}$ & 320 \\
\hline L10 & $7^{0} 28^{\prime} 46.17^{\prime \prime} \mathrm{N}$ & $5^{0} 44^{\prime} 18.62 " \mathrm{E}$ & 325 \\
\hline L11 & $7^{0} 28^{\prime} 47.82^{\prime \prime} \mathrm{N}$ & $5^{0} 44^{\prime} 12.08^{\prime \prime E}$ & 335 \\
\hline L12 & $7^{0} 28^{\prime} 50.99^{\prime \prime} \mathrm{N}$ & $5^{0} 44^{\prime} 13.82^{\prime \prime} \mathrm{E}$ & 346 \\
\hline
\end{tabular}

\section{Results}

\subsection{Dipole - dipole pseudo-sections along traverse TR1}

The calculated apparent resistivity values of the acquired field data were used to generate the pseudo-sections that is illustrated in Figure 5. The sections give the details of the lateral and vertical variations in ground apparent resistivity beneath each specific traverse line as opposed to the profile 1 that entailed 2-D vertical probing of the subsurface. The surface resistivity response beneath the T1 profile can be divided into three patterns.

The first pattern has a continuous low resistivity response with resistivity in the range of $27-139$ ohms-m. Its distribution is not continuous but appear in localized regions as pockets of resistivity material between stations 0 and 20, 45 and 50 and $140 \mathrm{~m}$ to the end of the traverse. The second layer delineated is the partly weathered layer/ fractured layer (green pseudo - section) with resistivity value ranging between 200 and 700ohms-m. This pattern is extensive and occur as the first pattern in some places along the profile where the localized pockets of low resistivity materials are absent. The third pattern is the fresh Basement (Yellow / Red coloration) having very high resistivity that 
approach infinity. On the pseudo section, there is an observable Basement depression between stations 45 and $50 \mathrm{~m}$. There is also a prominent fracture between station 80 and $100 \mathrm{~m}$. The Basement appears to be shallow in the region, occurring at the depth of approximately 3 $\mathrm{m}$.

\subsection{Dipole - dipole pseudo-sections along traverse TR2}

The calculated apparent resistivity values of the acquired field data were also used to generate the pseudo-sections that are illustrated in Figure 6. The sections give the details of the lateral and vertical variations in ground apparent resistivity beneath each specific traverse line as opposed to the profile 2 that entailed 2-D vertical probing of the subsurface. The surface resistivity response beneath the T2 profile can be divided into three patterns. The first pattern is continuous low resistivity response with resistivity in the range of $24-64 \mathrm{ohms}-\mathrm{m}$. Its distribution is not continuous but appear in localized regions as pockets of resistivity material between station 0 and 20,40 and 50 and 70 $\mathrm{m}$ to the end of the transverse. The second layer delineated is the partly weathered layer/ fractured layer (green pseudo - section) with resistivity values ranging between 225 and 942 ohms-m. This pattern is extensive and occurs as the first pattern in some places along the profile were the localized pocket of low resistivity materials are absent. The third pattern is the fresh Basement (Yellow / Red colouration) having very high resistivity that approach infinity. On the pseudo section, there is an observable Basement depression between stations 55 and $60 \mathrm{~m}$. There is also a prominent fracture between stations 62 and $65 \mathrm{~m}$. The Basement appears to be shallow in the region, occurring at the depth of approximately $2 \mathrm{~m}$.

The sections in figure 7 give the details of the lateral and vertical variations in ground apparent resistivity beneath each specific traverse line as opposed to the profile 3 that entailed 2-D vertical probing of the subsurface. The first pattern has a continuous low resistivity response with resistivity in the range of $36-64 \mathrm{ohm}-\mathrm{m}$. Its distribution is not continuous but appear in localized regions as pockets of resistivity material between station 0 and 36,50 and $63 \mathrm{~m}$ respectively to the end of the transverse. The second layer delineated is the partly weathered layer/ fractured layer (green pseudo - section) with resistivity value ranging between $489-1219 \mathrm{ohm}-\mathrm{m}$. This pattern is extensive and occurs as the first pattern in some places along the profile were the localized pocket of low resistivity materials are absent. The third pattern is the fresh Basement (Yellow / Red colouration) having very high resistivity that approach infinity. On the pseudo section, there is an observable Basement depression between station 60 and $70 \mathrm{~m}$. There is also a prominent fracture between stations 27 and $35 \mathrm{~m}$. The Basement appears to be shallow in the region, occurring at the depth of approximately $2.5 \mathrm{~m}$.
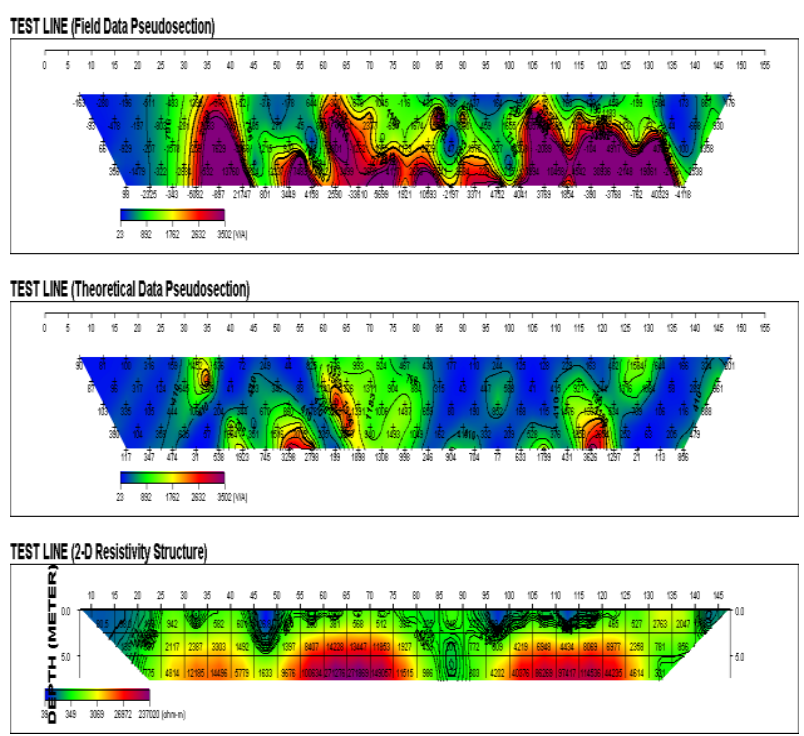

Fig. 5: Composite Plot of Pseudo- Section of Result of 2D Resistivity Inversion Beneath 1(A) Observed Resistivity Data, (B) Computed Resistivity Distribution and (C) Inverted Resistivity Structure.
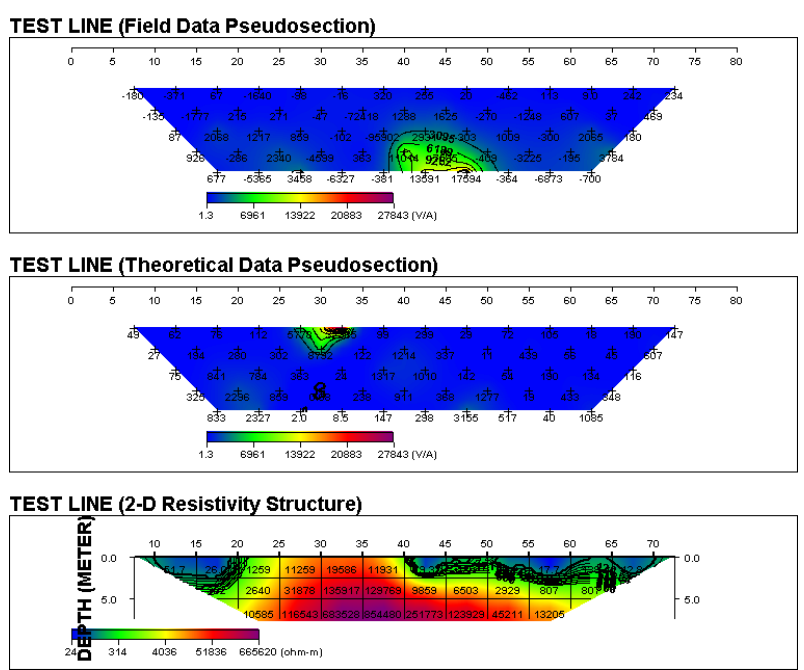

Fig. 6: Composite Plot of Pseudo- Section of Result of 2D Resistivity Inversion Beneath 2 (A) Observed Resistivity Data, (B) Computed Resistivity Distribution and (C) Inverted Resistivity Structure Dipole - Dipole Pseudo-Sections Along Traverse TR3. 


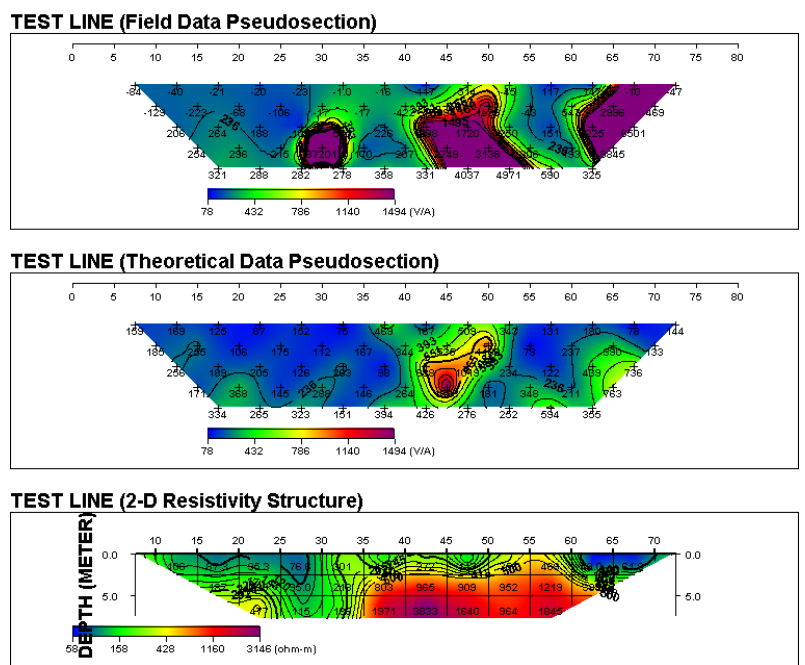

Fig. 7: Composite Plot of Pseudo- Section of Result of 2D Resistivity Inversion Beneath 3(A) Observed Resistivity Data, (B) Computed Resistivity Distribution and (C) Inverted Resistivity Structure.

\subsection{Geotechnical studies}

The natural moisture content of soil samples ranges from $27.4 \%$ to $37.8 \%$. The value of specific gravity of the unstable soil samples in the study area ranges between 2.59 and 2.75. According to Okogbue and Ene (2008), specific gravity is a reflection of the densities of constituent materials in each sample excluding the voids they contain

The soils were compacted at the standard proctor AASHTO level of compaction to determine the compaction level for sub-grade materials. The maximum density of failed building from the soil samples (MDD) ranges from $1290 \mathrm{~kg} / \mathrm{rn}^{3}$ to $1984 \mathrm{~kg} / \mathrm{rn}^{3}$ with optimum moisture content (OMC) ranging from $13.7 \%$ to $33.7 \%$, The MDD of all the soil samples have values less than the recommended value of 1984 $\mathrm{kg} / \mathrm{rn}^{3}$ for Nigeria soils. So, regardless of failed building sections, the soils can be regarded as poor sub-grade materials. For the consistency limits, the liquid limits value of the soil samples ranges from $51.3 \%$ to $64.6 \%$. While the plastic limits ranges from $18.0 \%$ to $29.9 \%$. Plasticity index ranges from $30.39 \%$ to $40.10 \%$.

The values of the unsoaked CBR for the soils ranges from $11 \%$ to $35 \%$. While the soaked CBR range from $5 \%$ to $13 \%$. The Federal Ministry of Works and Housing (1974) specified a minimum value of $11 \%$ and $15 \%$ for soak and unsoaked CBR for a sub-grade soil compacted OMC and MDD using BS proctor compaction method. Soil samples from unstable and stable portions have values less than the Federal Ministry of Works and Housing (1974) specification for the soaked CBR, hence, this may be responsible for their instability. Soaked and unsoaked percentages higher than the specified values may also be attributed to poor drainage construction. Soil samples from failed section in and around the locations falls within the specification for the unsoaked CBR, thus, making the soil samples suitable for road construction.

The activity (A) of a soil is the plasticity index (PT) divided by the clay content in the soil. Different types of clays have different specific surface areas which controls how much wetting is required to move a soil from one phase to another such as across the liquid limit or the plastic limit. From the activity, one can predict the dominant clay type present in a soil sample. High activity signifies large volume change when wetted and large shrinkage when dried. Normally the activity of clay is between 0.75 and 1.25 , and in this range clay is normal. It is assumed that the plasticity index is approximately equal to the clay fraction (A 1 ). When A is less than 0.75 , itis considered to be inactive. When it is greater than 1.25 , it is considered active. The values of the soil samples ranges from $467.3 \%$ to $485.0 \%$. The grain size of a soil is very important in making a number of important engineering property judgments. On the other hand, hydrolysis values range from $48.5 \%$ to $60.3 \%$.

\section{Conclusion and recommendations}

In this study, 2D electrical resistivity imaging technique has been employed to study the stability of materials around the Basement Complex rocks within Oroke High School, opposite Adekunle Ajasin University Campus, Akungba-Akoko, southwestern Nigeria.

The 2D dipole- dipole resistivity and pseudo - section delineated zones having resistivity values ranging from 200 to $700 \mathrm{ohm}-\mathrm{m}$ to infinity within a depth of 0-5 m. The electrical resistivity values of 27 to $139 \mathrm{ohm}$ meter within this zone, suggest the presence of clay. From the sections, there are indications of clay layers that form around the major basement depressions within the area; the depression is possibly a result of weathering of feldspar and amphibolites rich sections within the fresh basement as a result of preferential channeling and storage of groundwater.

From the probing of the subsurface sections, it could be observed that the resistivity of the top soil varies between 331 and $445 \mathrm{ohms}$ with average thickness ranging from 2 to $3 \mathrm{~m}$. From the study area as well, it was observed that the magnetic susceptibility is high which may likely be due to the presence of iron ore mineralization in the study area. The number and varying trend of faults is an evidence that the region has undergone more than one tectonic event. It was observed that there could be presence of fault within the basement of the subsurface on which the building is sited. Therefore, the study area is underlain by incompetent materials which cannot support building construction; however, the geologic structures beneath the subsurface create fractures.

Finally, electrical resistivity method is an effective measure or tool in site characterization. Therefore, it can be employed prior to any building construction proposal and engineering works and also it is useful in mapping of the sub-surface sequences. 


\section{Acknowledgement}

We acknowledge the technical members of staff of the Department of Earth Sciences, Adekunle Ajasin University, Akungba-Akoko for providing us with the necessary information, equipment and support.

\section{Appendix}

\section{DIPOLE- DIPOLE METHOD}

Traverse one

$\mathrm{a}=5, \mathrm{n}=1,5$, Total length $=80 \mathrm{~m}$

\begin{tabular}{|c|c|c|c|c|c|c|c|c|c|}
\hline NUMBER & 1 & 2 & 3 & 4 & 5 & 6 & 7 & 8 & 9 \\
\hline 1 & $-163 \Omega$ & $-280 \Omega$ & $-196 \Omega$ & $-511 \Omega$ & $-483 \Omega$ & $1399 \Omega$ & $-376 \Omega$ & $-52 \Omega$ & $-3 \Omega$ \\
\hline 2 & $-93 \Omega$ & $-478 \Omega$ & $-197 \Omega$ & $-803 \Omega$ & $-281 \Omega$ & $3283 \Omega$ & $-136 \Omega$ & $485 \Omega$ & $277 \Omega$ \\
\hline 3 & $66 \Omega$ & $-927 \Omega$ & $-207 \Omega$ & $-1578 \Omega$ & $-259 \Omega$ & $7629 \Omega$ & $-3368 \Omega$ & $1215 \Omega$ & $920 \Omega$ \\
\hline 4 & $356 \Omega$ & $-1479 \Omega$ & $-322 \Omega$ & $-2884 \Omega$ & $-532 \Omega$ & $13760 \mathrm{~m} \Omega$ & $324 \Omega$ & $2337 \Omega$ & $7483 \Omega$ \\
\hline 5 & $98 \Omega$ & $-2325 \Omega$ & $-343 \Omega$ & $-5082 \Omega$ & $-897 \Omega$ & $21747 \mathrm{~m} \Omega$ & $801 \Omega$ & $3449 \Omega$ & $4158 \Omega$ \\
\hline
\end{tabular}

\begin{tabular}{lllllll}
\hline NUMBER & 10 & 11 & 12 & 13 & 14 & 15 \\
\hline 1 & $-178 \Omega$ & $644 \Omega$ & $-300 \Omega$ & $678 \Omega$ & $1045 \Omega$ & $-116 \Omega$ \\
2 & $-45 \Omega$ & $3091 \Omega$ & $731 \Omega$ & $2337 \Omega$ & $-694 \Omega$ & $-1674 \Omega$ \\
3 & $142 \Omega$ & $6801 \Omega$ & $-1262 \Omega$ & $1055 \Omega$ & $1173 \Omega$ & $-2929 \Omega$ \\
4 & $942 \Omega$ & $3499 \Omega$ & $-2688 \Omega$ & $4117 \Omega$ & $2680 \Omega$ & $47 \Omega$ \\
5 & $2590 \Omega$ & $-33610 \Omega$ & $56994 \mathrm{~m} \Omega$ & $1921 \Omega$ & $10593 \mathrm{~m} \Omega$ & $-5341 \Omega$ \\
\hline
\end{tabular}

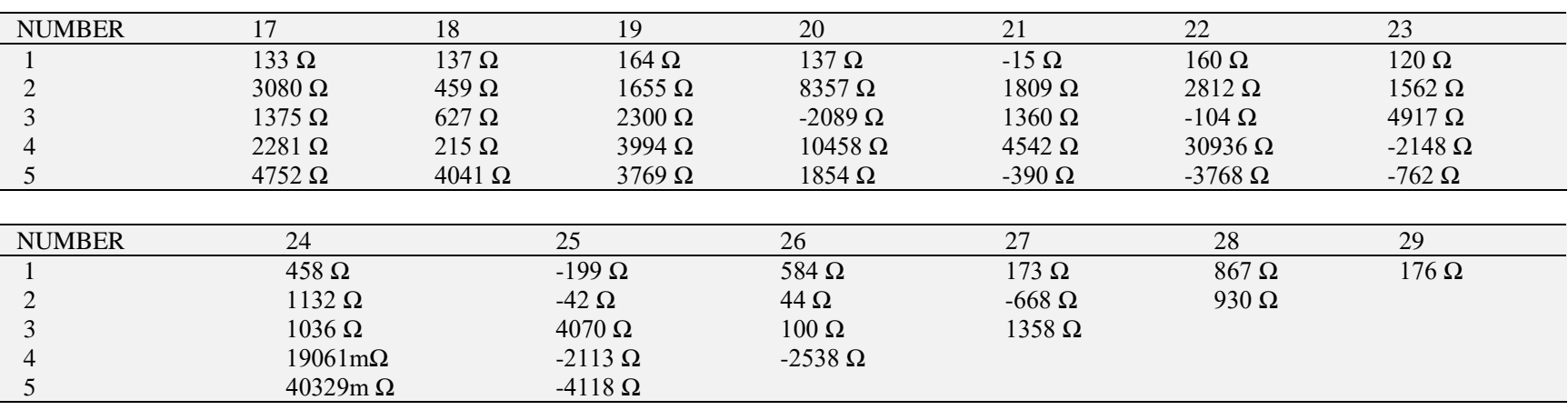

\section{TRAVERSE TWO}

$\mathrm{a}=5, \mathrm{n}=1,5$, Total length $=80 \mathrm{~m}$

\begin{tabular}{llllllll}
\hline NUMBER & 1 & 2 & 3 & 4 & 5 & 6 \\
\hline 1 & $-180 \Omega$ & $-371 \Omega$ & $67 \Omega$ & $-1640 \Omega$ & $-98 \Omega$ & $-16 \Omega$ \\
2 & $-135 \Omega$ & $-1777 \Omega$ & $215 \Omega$ & $271 \Omega$ & $-47 \Omega$ & $-72418 \mathrm{~m} \Omega$ \\
3 & $87 \Omega$ & $2068 \Omega$ & $1217 \Omega$ & $859 \Omega$ & $-102 \Omega$ & $-95902 \mathrm{~m} \Omega$ \\
4 & $926 \Omega$ & $-286 \Omega$ & $2340 \Omega$ & $-4599 \Omega$ & $363 \Omega$ & $11014 \Omega$ \\
5 & $677 \Omega$ & $-5365 \Omega$ & $3458 \Omega$ & $-6327 \Omega$ & $-381 \Omega$ & $13591 \Omega$ \\
\hline
\end{tabular}

\begin{tabular}{lllllll}
\hline NUMBER & 8 & 9 & 10 & 11 & 12 & 13 \\
\hline 1 & $255 \Omega$ & $20 \Omega$ & $-462 \Omega$ & $113 \Omega$ & $9 \Omega$ & $242 \Omega$ \\
2 & $1625 \Omega$ & $-270 \Omega$ & $-1248 \Omega$ & $607 \Omega$ & $37 \Omega$ & $469 \Omega$ \\
3 & $-303 \Omega$ & $1009 \Omega$ & $-300 \Omega$ & $2065 \Omega$ & $180 \Omega$ & \\
4 & $-409 \Omega$ & $-3225 \Omega$ & $-195 \Omega$ & $378 \Omega$ & & \\
5 & $-364 \Omega$ & $-6873 \Omega$ & $-700 \Omega$ & & \\
\hline
\end{tabular}

\section{Resistivity sounding field record}

\begin{tabular}{|c|c|c|c|c|c|c|}
\hline $\mathrm{AB} / 2$ & Ves1 & Ves2 & Ves3 & Ves4 & Ves5 & Ves6 \\
\hline 1 & 590 & 376 & 909 & 664 & 516 & 632 \\
\hline 2 & 469 & 291 & 531 & 431 & 327 & 455 \\
\hline 3 & 416 & 308 & 506 & 380 & 562 & 399 \\
\hline 4 & 418 & 379 & 322 & 333 & 230 & 358 \\
\hline 6 & 411 & 386 & 326 & 228 & 185 & 363 \\
\hline 6 & 430 & 374 & 278 & 384 & 162 & 356 \\
\hline 8 & 475 & 343 & 259 & 357 & 165 & 403 \\
\hline 12 & 616 & 380 & 311 & 385 & 182 & 496 \\
\hline 15 & 735 & 461 & 307 & 458 & 229 & 558 \\
\hline 15 & 797 & 496 & 408 & 456 & 276 & 557 \\
\hline 25 & 1380 & 754 & 603 & 685 & 295 & 804 \\
\hline 32 & 1737 & 818 & 723 & 876 & 446 & 857 \\
\hline 40 & 1976 & 1109 & 799 & 1182 & 636 & 963 \\
\hline 40 & 1667 & 1031 & 872 & 727 & 610 & 951 \\
\hline 65 & & 376 & 909 & 812 & 761 & - \\
\hline
\end{tabular}




\begin{tabular}{|c|c|c|c|c|}
\hline 100 & & & 664 & - \\
\hline $\mathrm{AB} / 2$ & Ves7 & Ves8 & Ves9 & Ves10 \\
\hline 1 & 250 & 896 & 1902 & 452 \\
\hline 2 & 203 & 640 & 1632 & 345 \\
\hline 3 & 171 & 506 & 1598 & 455 \\
\hline 4 & 148 & 1697 & 2269 & 697 \\
\hline 6 & 184 & 701 & 2689 & 391 \\
\hline 6 & 192 & 757 & 2621 & 415 \\
\hline 8 & 183 & 727 & 2600 & 308 \\
\hline 12 & 251 & 347 & 2313 & 759 \\
\hline 15 & 201 & 727 & 2723 & 760 \\
\hline 15 & 208 & 558 & 2332 & 277 \\
\hline 25 & 209 & 771 & 2006 & 255 \\
\hline 32 & 202 & 436 & 1043 & 926 \\
\hline 40 & 210 & 420 & 953 & 242 \\
\hline 40 & 212 & 1156 & 871 & 716 \\
\hline 65 & & & 800 & 950 \\
\hline 100 & & & & 120 \\
\hline
\end{tabular}

Table: Summary of the geological results of the Subgrade soil under investigation

\begin{tabular}{|c|c|c|c|c|c|c|c|c|c|c|c|c|}
\hline $\begin{array}{l}\text { Depth/ } \\
\text { Location } \\
(1.5 \mathrm{~m})\end{array}$ & $\begin{array}{l}\text { Moisture } \\
\text { Content } \\
(\%)\end{array}$ & $\begin{array}{l}\text { Liquid } \\
\text { Limit } \\
(\%)\end{array}$ & $\begin{array}{l}\text { Plastic } \\
\text { Limit } \\
(\%)\end{array}$ & $\begin{array}{l}\text { Linear } \\
\text { shrinkage } \\
(\%)\end{array}$ & $\begin{array}{l}\text { Plastic- } \\
\text { ity In- } \\
\operatorname{dex}(\%)\end{array}$ & $\begin{array}{l}\text { Parti- } \\
\text { cle } \\
\text { Size } \\
(\%)\end{array}$ & $\begin{array}{l}\mathrm{MDD} \\
\left(\mathrm{Kg} / \mathrm{m}^{3}\right)\end{array}$ & $\begin{array}{l}\text { OMC } \\
(\%)\end{array}$ & $\begin{array}{l}\text { Unsoaked } \\
\text { (\%) CBR }\end{array}$ & $\begin{array}{l}\text { Soaked } \\
(\%) \\
\text { CBR }\end{array}$ & $\begin{array}{l}\text { Specific } \\
\text { Gravity }\end{array}$ & $\begin{array}{l}\text { Hydrol- } \\
\text { ysis } \\
(\%)\end{array}$ \\
\hline L1 & 28.1 & 55.1 & 18.0 & 5.8 & 37.12 & 471.3 & 1290 & 33.7 & 11 & 6 & 2.59 & 48.5 \\
\hline L2 & 31.6 & 51.3 & 24.7 & 6.8 & 34.30 & 473.0 & 1953 & 14.6 & 34 & 11 & 2.67 & 48.8 \\
\hline L3 & 37.8 & 54.5 & 28.7 & 6.8 & 34.15 & 472.1 & 1564 & 25.8 & 19 & 6 & 2.75 & 55.1 \\
\hline L4 & 27.4 & 57.0 & 24.7 & 7.7 & 33.99 & 478.0 & 1869 & 17.0 & 30 & 13 & 2.71 & 52.2 \\
\hline L5 & 29.3 & 55.5 & 24.9 & 6.3 & 30.39 & 483.6 & 1865 & 17.1 & 27 & 11 & 2.63 & 60.3 \\
\hline L6 & 28.2 & 59.1 & 24.2 & 8.2 & 31.49 & 485.0 & 1854 & 17.4 & 29 & 10 & 2.64 & 52.1 \\
\hline L7 & 34.1 & 63.1 & 29.2 & 7.2 & 38.20 & 482.6 & 1599 & 24.8 & 15 & 5 & 2.72 & 55.6 \\
\hline L8 & 37.8 & 62.4 & 24.7 & 6.8 & 36.36 & 484.0 & 1984 & 13.7 & 35 & 12 & 2.64 & 52.1 \\
\hline L9 & 37.8 & 62.4 & 24.7 & 5.8 & 37.70 & 479.8 & 1539 & 26.5 & 19 & 7 & 2.75 & 48.5 \\
\hline L10 & 33.4 & 64.6 & 29.9 & 6.3 & 40.10 & 478.5 & 1546 & 26.3 & 17 & 9 & 2.71 & 48.8 \\
\hline L11 & 37.4 & 62.6 & 24.1 & 6.8 & 38.10 & 467.3 & 1315 & 33.0 & 13 & 7 & 2.66 & 55.1 \\
\hline L12 & 33.0 & 62.9 & 24.0 & 7.7 & 38.88 & 469.5 & 1879 & 16.7 & 32 & 9 & 2.71 & 55.2 \\
\hline
\end{tabular}

\section{References}

[1] Aigbedion, I. (2007). Geophysical Investigation of road failure Using Electromagnetic Profile along Opoji, Uwelench and Illeh in Ekpoma, Nigeria. Middle East Journal of Scientific Research 2(3-4):111-115. https://doi.org/10.1007/BF02594951.

[2] Ademeso, O. A. and Adeyeye, O. (2011). The petrography and major element geochemistry of the granite gneiss of Arigidi area, S/W Nigeria. Nature and Science, 9 (5): 7-12.

[3] Adeyemi, G. O. (1990). Clay mineralogy, major elements geochemistry and strength characteristics of three highway subgrade soils in Southwestern Nigeria. Bulletin of the international Association of Engineering Geology, 50: 5-8.

[4] Aminu, M. B., Akande, T. M., and Ishola, O. A. (2014). 2D geoelectric imaging of the Uneme - Nekhua fracture zone. International Journal of Geophysics; 8 https://doi.org/10.1155/2014/842812.

[5] Fajana, A. O. Olaseeni, O.G., Bamidele, O.E. and Olabode, O. P. (2016). Geophysical and Geotechnical investigation for post-foundation studies, Faculty of Social Sciences and Humanities, Federal University, Oye-Ekiti. FUOYE Journal of Engineering and Technology, 1(1): 62-66 https://doi.org/10.46792/fuoyejet.v1i1.17.

[6] Gidigasu, M.D. (1972). Characterization and the use of Tropical Gravels for Pavement Constructing in West Africa, Geotechnical engineering, 9:219-260. https://doi.org/10.1007/BF00881742.

[7] Meshida, E.A. (1985) Engineering properties of lateritic soils of some part of SW Nigeria, unpublished PhD Thesis, University of Ife, Ile-Ife, Nigeria

[8] Momoh, L.O., Akintorinwa, O. J andOlorunfemi, M. O. (2008). Geophysical Investigation of Highway Failure - A case Study from the Basement Complex Terrain of Southwestern Nigeria. Journal of Applied Sciences, 4 (6): 637 - 648.

[9] Okogbue, C. O. and Ene, E. (2008). Geochemical and geotechnical characteristics, and the potential for use in drilling mud, of some clay bodies in southeastern Nigeria. Journ Min Geol., 44 (2):121-130 https://doi.org/10.4314/jmg.v44i2.49017.

[10] Oyedele, K.F and Bankole, O.O. (2009). Subsurface stratigraphic mapping using geophysics and its impact on urbanization development in Arepo area. Ogun State, Nigeria. New York Science Journal 2(2):31 - 45. 